\title{
CHINA COLLECTION 2.1: AEROSOL OPTICAL DEPTH DATASET FOR MAINLAND CHINA AT 1KM RESOLUTION
}

\author{
YongXue ${ }^{1,2}$, Xingwei He ${ }^{1,4}$, Hui Xu1 ${ }^{1,4}$, Jie Guang ${ }^{1}$, Jianping Guo ${ }^{3}$, and Linlu Mei ${ }^{l}$
}

${ }^{1}$ Key Laboratory of Digital Earth Science, Institute of Remote Sensing and Digital Earth, Chinese Academy of Sciences, Beijing 100101, China

${ }^{2}$ Faculty of Life Sciences and Computing, London Metropolitan University, 166-220 Holloway Road, London N7 8DB, UK

${ }^{3}$ Centre for Atmosphere Watch and Services, Chinese Academy of Meteorological Sciences, China Meteorological Administration, Beijing 100081, China
${ }^{4}$ University of Chinese Academy of Sciences, Beijing 100049, China

\begin{abstract}
A wide range of data products have been published since the operation of the Moderate Resolution Imaging Spectroradiometer (MODIS) sensor on NASA's TERRA and AQUA satellites. Based on DarkTarget and DeepBlue method, NASA has published Aerosol Optical Depth (AOD) products Collection 6.0 with spatial resolution of $3 \mathrm{~km}$. Although validated globally, regional and systematic errors are still found in the MODIS-retrieved AOD products. This is especially remarkable for bright heterogeneous land surface, such as mainland China. In order to solve the aerosol retrieval problem over heterogeneous bright land surface, the Synergetic Retrieval of Aerosol Properties algorithm (SRAP) has been developed based on the synergetic use of the MODIS data of TERRA and AQUA satellites. Using the SRAP algorithm, we produced AOD dataset-China Collection 2.1 at $1 \mathrm{~km}$ spatial resolution, dated from August 2002 to 2012. We compared the China Collection 2.1 AOD datasets for 2010 with AERONET data. From those 2460 collocations, representing mutually cloud-free conditions, we find that $62 \%$ of China Collection 2.1 AOD values comparing with AERONET-observed values within an expected error envelop of $20 \%$ and $55 \%$ within an expected error envelop of $15 \%$. Compared with MODIS Level 2 aerosol products, China Collection 2.1 AOD datasets have a more complete coverage with fewer data gaps over the study region.
\end{abstract}

Index Terms-Aerosol Optical Depth (AOD), Synergetic Retrieval of Aerosol Properties (SRAP), Moderate Resolution Imaging Spectroradiometer (MODIS), China Collection 2.1

\section{INTRODUCTION}

Aerosols play a significant role in earth-atmospheric radiant balance and global climate changes. These suspended airborne particles scatter solar radiation back, absorb solar radiation in the atmosphere, and shade the earth's surface. Airborne particles act as cloud condensation nuclei entering into cloud processes and thereby change cloud reflectivity and the hydrological cycle $[1,2]$. Aerosols also affect human health and reduce visibility [3]. So accurate aerosol monitoring is very significant. Satellite remote sensing can get the Earth's atmospheric and underlying information macroscopically and dynamically.

There are two main AOD retrieval algorithms using MODIS data: dark dense vegetation (DDV) and deep blue. By using MODIS data, the DDV algorithm has showed excellent competence at the aerosol distribution and properties retrieval, which uses the dark-target approach and assumes the ratio of surface reflectance between $0.47 \mu \mathrm{m}(0.64 \mu \mathrm{m})$ and $2.1 \mu \mathrm{m}$ is 0.25 $(0.5)[4,5]$. This assumption is valid for most vegetated land surfaces. However, over desert regions, land surface reflectance significantly deviates from this assumption. Deep blue is a new algorithm for aerosol retrieval over some bright surfaces [6, 7]. It employs the fact that the reflectance over bright areas is much darker in the blue spectral region (i.e., wavelength $<500 \mathrm{~nm}$ ) than that in other spectral regions. This algorithm has been applied to MODIS, Sea-viewing Wide Field of view Sensor (SeaWiFS) and GLobal Imager (GLI) satellite data, and it can provide a global AOD of approximately $1 \mathrm{~km} \mathrm{x} 1 \mathrm{~km}$ resolution over bright surfaces on a daily basis.

In order to solve the aerosol retrieval problem over bright land surface, the SRAP algorithm has been developed based on the synergetic using of the MODIS data of TERRA and AQUA satellites $[8,9,10]$. Using SRAP algorithm, surface reflectance and AOD can be simultaneously retrieved over various ground types including higher reflective surface such as urban areas. The SRAP algorithm is introduced in Section 2. In Section 3, the data, results and comparisons with AErosol Robotic NETwork (AERONET) AOD data and NASA-MODIS AOD data are presented. A summary and conclusions are given in Section 4. 


\section{MODELS AND METHODS}

\subsection{SRAP Model}

Through the binary observation, SRAP construct the closed equation, retrieve AOD over complex surface (such as city, arid, desert). It can be written as follows[8, 9, 10]:

$$
\left\{\begin{aligned}
A_{i, j} & =\frac{\left(A_{i, j}^{\prime} b-a_{i}\right)+a_{i}\left(1-A_{i, j}^{\prime}\right) \mathrm{e}^{\left(a_{i}-b\right) \varepsilon\left[\tau_{R}+\tau_{A}\right]}}{\left(A_{i, j}^{\prime} b-a_{i}\right)+b\left(1-A_{i, j}^{\prime}\right) \mathrm{e}^{\left(a_{i}-b\right) \varepsilon\left[\tau_{R}+\tau_{A}\right]}} \\
\tau_{R} & =0.00879 \lambda^{-4.09} \\
\tau_{A} & =\beta_{i} \lambda^{-\alpha} \\
\frac{A_{1, j}}{A_{2, j}} & =K
\end{aligned}\right.
$$

Where $i=1,2$ means the two satellite observations, $j=1,2,3$ means the three bands of 470, 550, 660nm; $a_{i}=\sec \theta_{i}, b=2$ and $\varepsilon=$ 0.1. In SRAP, the Angstrom wave exponent $\alpha$ is regarded as a constant and $\beta$ is varied for two observations. The ratio $K$ of the surface reflectance of the two observations is a constant, which is assumed to depend only on the variation of the surface reflectance with the geometry and to be independent of the wavelength.

\section{DATA AND RESULTS}

\subsection{Data}

The MODIS instrument is operating on both the Terra and Aqua spacecraft. It has a viewing swath width of $2,330 \mathrm{~km}$ and views the entire surface of the Earth every one to two days. Its detectors measure 36 spectral bands between 0.405 and $14.385 \mu \mathrm{m}$, and it acquires data at three spatial resolutions $-250 \mathrm{~m}, 500 \mathrm{~m}$, and $1,000 \mathrm{~m}$. TERRA was launched on December 12, 1999 and flies northward pass the equator at about local time 10:30 AM. AQUA, launched on May 4, 2002, flies southward pass the equator at about local time 1:30 PM. The time interval of the two satellites passing over the same area is usually less than 3 hours. In our method, four visible MODIS L1B bands $(0.47,0.55,0.66$ and $1.38 \mu \mathrm{m})$ data $(\mathrm{C} 5)$ were used.

To validate the AOD results, we used the 38 Aerosol Robotic Network (AERONET) sites in the study area. The AERONET data measured by sun photometer include AOD at different bands, Angstrom coefficients and many other aerosols' physical/optical parameters $[11,12]$. The AOD data we used for validation are Level 2.0 products which have good quality assurance. Table 1 contains information of the latitude, longitude of selected AERONET sites.

\subsection{Results}

Fig. 1 shows the distribution of AOD over China averaged from the China Collection 2.0 AOD datasets during the period of 20022012. From the figure we can see that the areas with high AOD values include the North China Plain, Tarim Basin, Sichuan Basin, Tibetan Plateau, and middle and lower reaches of the Yangtze River; in contrast, in Fujian Province, the Yungui Plateau and Northeast Plain, the AOD values are low. Besides we analyze the distribution of the month and season average AOD and find that for monthly average AOD is generally high in China's eastern coastal region from March to August, and AOD is not more than 0.5 in other months. Season averaged results show that the higher values of AOD are mostly distributed in eastern and southern China.
Fig. 2 is the seasonal aerosol distribution for the 2010. In spring, most regions in the eastern China are affected by the sand storms which directly affect the aerosol levels. In summer, the spatial distribution characteristics of AOD like spring, the AOD values up to 1.1 in Hebei, Henan, and Shandong. In autumn, the AOD values of the whole research area are relatively low, in most of the region it is lower than 0.3 , the high value of AOD was mainly distributed in the developed area of Southeast China and the AOD values in general are about 0.7. In winter, there is not special AOD high value and basically below 0.5 . The increase of the AOD in the Sichuan Basin is probably associated with poor dispersion conditions and heavy local industrial emissions.

We compared the AOD results with AErosol Robotic NETwork (AERONET). Fig. 3 shows China Collection 2.1 AODs at $550 \mathrm{~nm}$ collocated with AERONET AODs at the same wavelength for both (the union of) the Terra and Aqua datasets in the year of 2010. The data are sorted according to ordered pairs (AERONET, MODIS) of AODs in 0.025 intervals; each colour represents the number of cases (colour bar) with that particular ordered pair value. The dashed, dotted and solid lines are the 1-1 lines, the $\mathrm{EE}$ for land $\mathrm{AOD} \pm(0.05+0.15)$, and the linear regression of the scatterplot, respectively. The text at the top describes the number of collocations $(\mathrm{N})$, the percentage within expected error, the regression curve, correlation (R), and the RMS error of the fit. From those 2460 collocations representing mutually cloud-free conditions, We find that $62 \%$ of China Collection 2.1 AOD values are within an expected error (EE) range of $\pm(0.05+20 \%)$ and that $56 \%$ are within an EE range of $\pm(0.05+15 \%)$ when compared with AERONET-observed values. For CARSNET validation, we find that $60 \%$ of China Collection 2.1 AOD values are within an expected error (EE) range of $\pm(0.05+20 \%)$ and that $53 \%$ are within an EE range of $\pm(0.05+15 \%)$.

The ratio of retrievable products such as the SRAP-MODIS, Dark Target and Deep Blue AODs in August 2010 are shown in Fig. 4. It is very clear that the China Collection 2.1 AOD datasets have more complete coverage with fewer data gaps over the study region than do the MODIS AOD products. The fraction of retrievable area is about $60 \%-80 \%$ for SRAP and below $20 \%$ for DT and DB algorithms.

\section{CONCLUTION}

The China Collection 2.1 AOD datasets have more coverage with fewer data gaps over the study region than that from the MODIS AOD products. In China, many regions are not satisfied with the dark density pixel condition set by MODIS AOD DDV algorithm. Besides, the accuracy of the MODIS-retrieved China Collection2.1 AOD datasets over land was evaluated by comparing satellitebased measurements to AERONET ground-based sun photometer observations. The results of the comparison indicate that the China Collection 2.1 AOD dataset agrees well with the AERONET AODs.

So far, there is no AOD datasets throughout the whole of China with a resolution of about $1 \mathrm{~km}$ or higher, Aerosol is playing increasingly important role in Regional and Global climate change. So we can use the China Collection 2.1 AOD to analysis the change of AOD distribution over China, and further analysis the pollution source and air quality. 


\section{ACKNOWLEDGMENTS}

This work was supported in part by the NSFC, China under Grants 41271371, 41471306, and the Ministry of Science and Technology (MOST) of China under Grant No. 2013CB733403. The MODIS data come from NASA Goddard Space Flight Center, Level 1 and Atmosphere Archive and Distribution System (LAADS Web) and the ground measurement data for validation are from seven AERONET sites in China. The authors thank all the principal investigators and their staff for providing the data and products used in this investigation.

\section{References}

[1] Twomey, S. A., "The influence of pollution on the short wave albedo of clouds". J. Atmos. Sci., 34, 1149-1152, 1977.

[2] Rosenfield, D., and I. M. Lensky, "Satellite-based insights into precipitation formation processes in continental and maritime convective clouds". Bull. Amer. Meteor. Soc., 79, 2457-2476, 1998.

[3] Samet, J. M., S. L. Zeger, F. Dominici, F. Curriero, I.Coursac, D.W. Dockery, J. Schwartz, and A. Zanobetti, 2000: The national morbidity, mortality, and air pollution study, Part II:Morbidity, mortality, and air pollution in the United States. Health Effects Institute Research Rep. 94, Cambridge, MA,87 pp.

[4] Y.J. Kaufman, D. Tanré, L. A. Remer, E. F. Vermote, D. A. Chu, andB. N. Holben, "Operational remote sensing of tropospheric aerosol overland from EOS Moderate Resolution Imaging Spectroradiometer" Journal of Geographical Research, vol. 102, no. D14, pp. 17051-17067, 1997.

[5] Y. J. Kaufman, A. E.Wald, L. A. Remer, B. C. Ago, R. R. Li, and L. Flynn,"The MODIS $2.1 \mu \mathrm{m}$ channel-Correlation with visible reflectance foruse in remote sensing of aerosol," IEEE Transactions on Geosciences and Remote Sensing,vol. 35, no. 5, pp. 1286-1298, 1997.

[6] N.C. Hsu, S.C. Stay, M.D. King, and J.R. Herman, "Deep Blue Retrievals of Asian Aerosol Properties during ACE-Asia," IEEE Transactions on Geosciences and Remote Sensing, vol. 44, no. 11, pp. 3180-3195, 2006.

[7] N.C. Hsu, S.C. Stay, M.D. King, and J.R. Herman, "Aerosol Properties over Bright-Reflecting Source Regions," IEEE Transactions on Geosciences and Remote Sensing, vol. 42, no. 3, pp. 557-569, 2004.

[8] J. Tang, Y. Xue, T. Yu, and Y. Guan, "Aerosol optical thickness determination by exploiting the synergy of TERRA and AQUA MODIS," Remote Sensing of Environment, vol. 94, no. 3, pp. 327-334, 2005.

[9] Y. Xue, and A. Cracknell, "Operational bi-angle approach to retrieve the Earth surface albedo from AVHRR data in the visible band," Remote Sensing, vol. 16, no. 3, pp. 417-429, 1995.

[10] Y. Xue, X. He and H. Xu, CHINA COLLECTION 2.0: The Aerosol Optical Depth Dataset from the Synergetic Retrieval of Aerosol Properties Algorithm. Atmospheric Environment, Volume 95, pp 45-58, 2014.

[11] Holben B N, Vermote E, Kaufman Y J, et al. "AERONET-A federated instrument network and data archive for aerosol characterization".Remote Sens Environ, pp.1-16, 1998.

[12] Dubovik O, King M D. "A flexible inversion algorithm for retrieval of aerosol optical properties from sun and sky radiance measurements". JGeophys Res, vol.105, no.D16, pp. 20673-20696, 2000 .
Table1.Selected AERONET stations in the Asian region and their locations for the aerosol retrieval validation.

\begin{tabular}{|c|c|c|c|}
\hline Num & Name & $\begin{array}{l}\text { Latitud } \\
\text { e } \\
\text { (Degree } \\
\text { North) } \\
\end{array}$ & $\begin{array}{l}\text { Longitud } \\
\text { e (Degree } \\
\text { East) }\end{array}$ \\
\hline 1 & Bac_Giang & 21.29 & 106.23 \\
\hline 2 & Beijing & 39.98 & 116.38 \\
\hline 3 & Chiang_Mai_Met_Sta & 18.77 & 98.97 \\
\hline 4 & EVK2-CNR & 27.96 & 86.81 \\
\hline 5 & Gosan_SNU & 33.29 & 126.16 \\
\hline 6 & Gwangju_GIST & 35.23 & 126.84 \\
\hline 7 & Hangzhou-ZFU & 30.26 & 119.73 \\
\hline 8 & Hefei & 31.91 & 117.16 \\
\hline 9 & Hong_Kong_Hok_Tsui & 22.21 & 114.26 \\
\hline 10 & Hong_Kong_Poly $\bar{U}$ & 22.30 & 114.18 \\
\hline 11 & Irkutsk & 51.80 & 103.09 \\
\hline 12 & Issyk-Kul & 42.62 & 76.98 \\
\hline 13 & Kaiping & 22.32 & 112.54 \\
\hline 14 & Kanpur & 26.51 & 80.23 \\
\hline 15 & Karachi & 24.87 & 67.03 \\
\hline 16 & Lulin & 23.47 & 120.87 \\
\hline 17 & Mukdahan & 16.61 & 104.68 \\
\hline 18 & Nainital & 29.36 & 79.46 \\
\hline 19 & NAM_CO & 30.77 & 90.96 \\
\hline 20 & NCU_Taiwan & 24.97 & 121.19 \\
\hline 21 & Noto & 37.33 & 137.14 \\
\hline 22 & NUIST & 32.21 & 118.72 \\
\hline 23 & Osaka & 34.65 & 135.59 \\
\hline 24 & Pantnagar & 29.05 & 79.52 \\
\hline 25 & PKU_PEK & 39.59 & 116.18 \\
\hline 26 & Pune & 18.54 & 73.81 \\
\hline 27 & Shirahama & 33.69 & 135.36 \\
\hline 28 & Shouxian & 32.56 & 116.78 \\
\hline 29 & Taihu & 31.42 & 120.22 \\
\hline 30 & Taipei_CWB & 25.03 & 121.50 \\
\hline 31 & Tomsk & 56.48 & 85.05 \\
\hline 32 & Ussuriysk & 43.70 & 132.16 \\
\hline 33 & XiangHe & 39.75 & 116.96 \\
\hline 34 & Xinglong & 40.40 & 117.58 \\
\hline
\end{tabular}

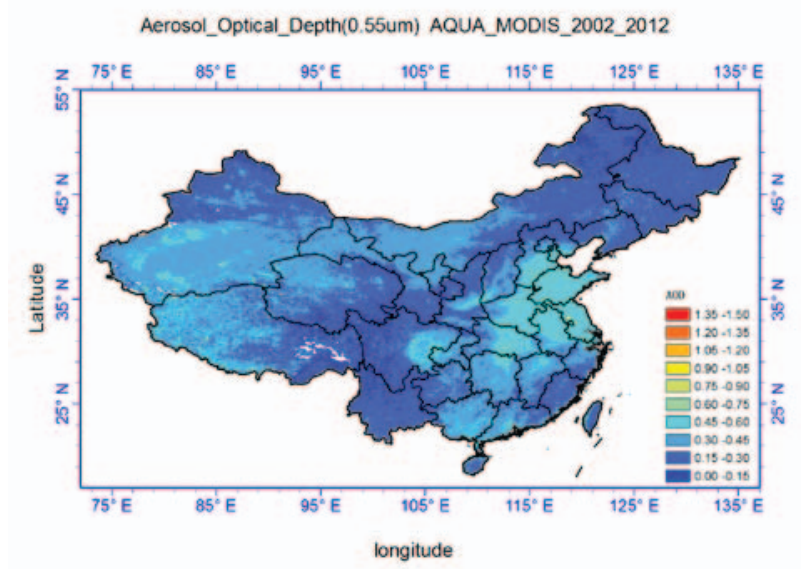

Fig. 1. The distribution of AODs over China averaged during the period of 2002-2012 

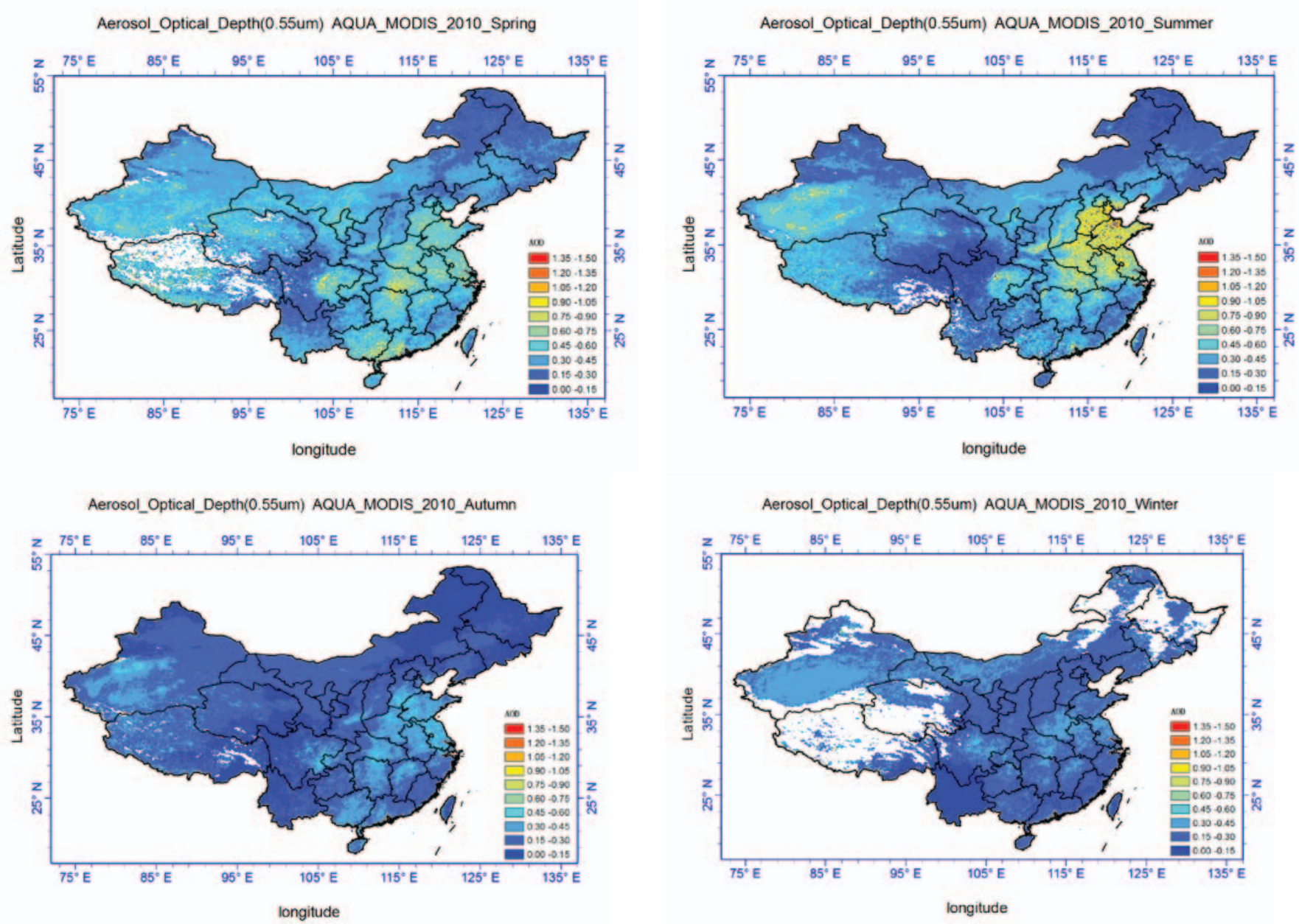

Fig2. Thefour-season distribution of AODs over China averaged fromthe China Collection 2.1 AOD datasetsin 2010.
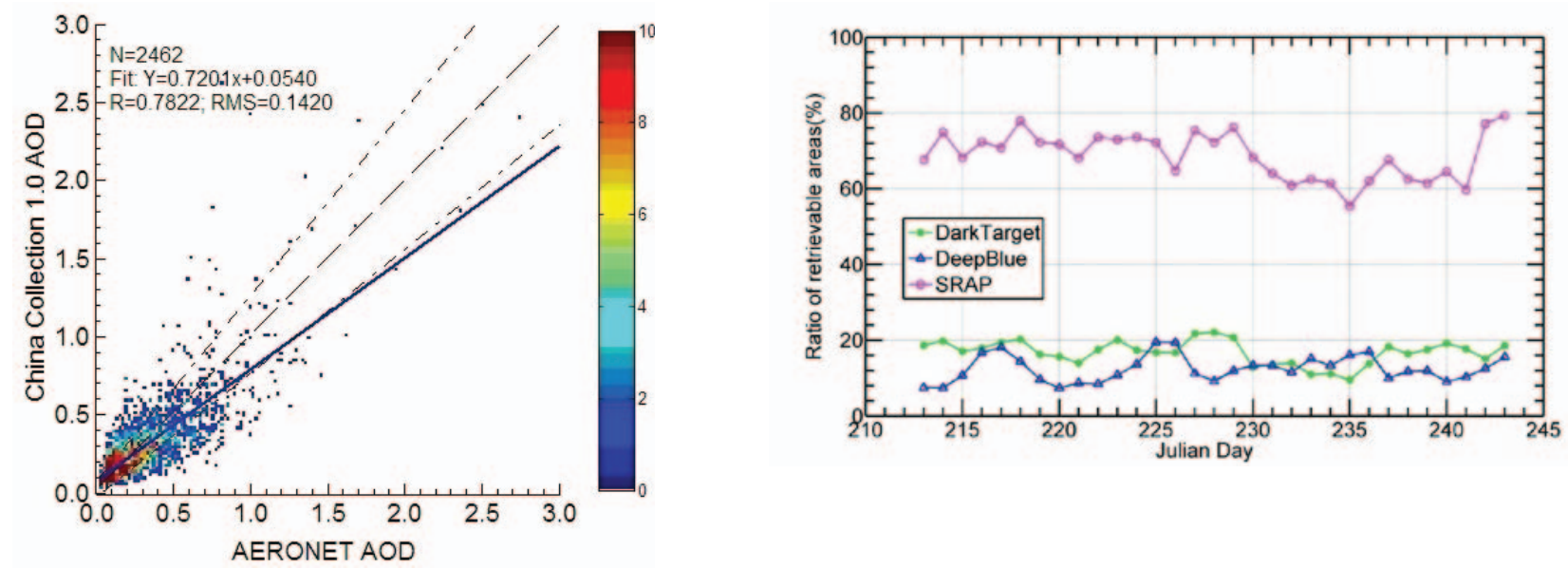

Fig3. The China Collection 2.1 AODs at $550 \mathrm{~nm}$ were collocated with AERONET for the same wavelength for both the Terra and Aqua datasets for 2010

Fig. 4 The ratio of retrievable AODs areas by SRAP, the Dark Target and Deep Blue method 